\title{
TWO MODELS OF THE CRIMINAL JUSTICE SYSTEM: AN ORGANIZATIONAL PERSPECTIVE
}

\author{
MALCOLM M. FEELEY Yale Law School
}

AUTHOR'S NOTE: This article is a revision of a paper prepared for delivery at the 1971 Annual Meeting of the American Political Science Association, Conrad Hilton Hotel, Chicago, Illinois, September 9, 1971. I wish to acknowledge the support of the National Science Foundation, through an institutional grant to New York University and the Graduate Arts and Science Research Fund of the Graduate School of New York University. Also, my thinking on this topic has benefited greatly from discussion with Susan White and Stefan Kapsch, and I must acknowledge my indebtedness to them.

\section{INTRODUCTION}

Despite the scholarly and popular interest in the administration of criminal justice, there are few theoretical discussions of the process. Consequently, this paper is an attempt to develop an explicit theoretical framework by which the practices in the administration can be depicted and explained. In it I characterize the criminal justice system in terms of the theory of large-scale organizations, and then examine some of the tasks of administration in terms of established concepts and criteria supplied by this perspective. Following Etzioni, by organization I mean "social units devoted primarily to the attainment of specific goals" (1961). In this case the formal task of the criminal justice system is to process arrests, determine guilt or innocence, and in the case of guilt to specify an appropriate sanction. The major actors in the organization include the defendant, prosecutor, defense counsel, judge, arresting officer, court clerk, and to varying degrees, other persons such as witnesses, additional policemen, clerks, parole officers, court psychiatrists and social workers, and the defendants' families and friends. A system of the administration of justice, whether it is adversarial or inquisitorial, entails the key elements of organization: institutionalized interaction of a large number of actors whose roles are highly defined, who are required to follow highly defined rules and who share a responsibility in a common goal - that of processing arrests. ${ }^{x}$

In this discussion, I will outline two models of, or approaches to, organizational analysis and then use them to 
characterize and evaluate much of the recent systematic research on the administration of criminal justice. Finally, some of the concerns raised by the theories of large-scale organizations generally, but which have been over-looked by students of the administration of justice, will be examined.

\section{TWO MODELS OF ORGANIZATION AND A MODIFICATION}

At the risk of oversimplification, let me suggest that a good portion of the systematic studies of the administration of justice in the United States can be classified into two general models of organization - models which I have adapted from Etzioni's discussion of organizational analysis. They are the goal model and the functional-systems model (1960). The former, he argues, is an approach which is concerned primarily with "organizational effectiveness," in which the criteria for the assessment of effectiveness is derived from organizational goals (Etzioni, 1960: 257). Thus the announced public goals of an organization are usually regarded as the "source for standards by which actors assess the success of their organization" (Etzioni, 1960: 257). This approach, its adherents claim, facilitates an "objective" analysis because it does not insert the observer's own values, but takes the "values," i.e., the goals, of the organization as the fixed criteria of judgment. On the other hand, Etzioni (1960: 259) identifies what he has termed the functional-systems model of organizational analysis. It is sharply distinguished from the goal model in that:

the starting point for this approach is not the goal itself, but a working model of a social unit which is capable of achieving a goal. Unlike a goal, or a set of gcal activities, it is a model of a multi-functional unit. It is assumed $a$ priori that some means have to be devoted to such non-goal functions as service and custodial activities, including means employed for the maintenance of the unit itself. From the viewpoint of the system model, such activities are functional and increase the organizational effectiveness.

The key difference between the models, Etzioni argues, is that the latter approach is more open-ended in its analysis of the function and "needs" of an organization than is the former, and the researcher is likely to be more attentive to a wide range of influencing factors and as a result apt to show a less biased point of view.

In applying this very general typology to an analysis of approaches to the study of the administration of criminal justice, I have made certain adjustments. In particular it seems 
appropriate to join the goal model with Weber's rational-legal model of organization, and produce what I call a rational-goal model of the criminal justice system. Etzioni has identified the key distinction between these two models. The rational model "differs from the goal model by the types of functions that are included as against those that are neglected. The rational model is concerned almost solely with means activities, while the goal model focuses attention on goal activities" (Etzioni, 1960: fn. 16, 263). In the administration of criminal justice, however, it is possible to join these two models, because means and goals merge. While on a highly abstract level, the goal - as opposed to the means - of the criminal justice system might be stated in terms of achieving justice, this goal has no clear empirical referent or context by itself. In the dominant tradition of the West at least, the goal, justice, usually acquires meaning in a normative, legal, and empirical context, only when operationalized in terms of procedure, i.e., means." Thus, particularly in the administration of justice, the means become the end, at least in terms of viewing "organizational effectiveness" and "formal goal activities."3

\section{THE RATIONAL-GOAL MODEL}

There is a large body of research focusing primarily upon means or formal goals of the administration of criminal justice. Although there is no consensus or common methodology among the writers adopting this rational-goal approach, their common theme is a primary concern with formal rules. One approach in this style of research is the logical analysis of the inter-relationship of the rules of criminal procedure in order to identify and overcome problems of ambiguity, fairness, and discretion. These studies are analogous to the analysis and continuous refinement of formal organizational schema. Another form of research this model uses is the empirical description of practices in the administration of justice, which is then contrasted to the formal rules and goals of the system in an attempt to identify and measure discrepancies between reality and ideal.

This preoccupation with formal goals and rules has as its most eloquent theoretical spokesman Max Weber, who regarded the organization of the administration of justice in the West as the prime example of rational organization. According to Weber, the drift of history in the West has been an ever-increasing reliance upon rational modes of thinking, organization, and authority (1954). In terms of organization this has resulted in a system of de-personalized, rule-bound, and hierarchically 
structured relationships, which produce highly predictable, rationalized, and efficient results. The system of the administration of justice, he argued, is an excellent example of this phenomenon (Weber, 1954: 350):

Above all, bureaucratization offers the optimal possibility for the realization of the principle of division of labor in adminstration according to purely technical considerations, allocating individual tasks to functionaries who are trained as specialists and who continuously add to their experience by constant practice. "Professional" execution in this case means primarily execution "without regard to person" in accordance with calculable rules. The consistent carrying through of bureaucratic authority produces a leveling of differences in social "honor" or status, and, consequently, unless the principle of freedom in the market is simultaneously restricted, the universal sway of economic "class position." The fact that this result of bureaucratic authority has not always appeared concurrently with bureaucratization is based on the diversity of the possible principles by which political communities have fulfilled their tasks. But for modern bureaucracy, the element of "calculability of its rules" has really been of decisive significance. . . . Bureaucracy provides the administration of justice with a foundation for the realization of a conceptually systematized rational body of law on the basis of "laws" as it was achieved for the first time to a high degree of technical perfection in the late Roman Empire.

On the formal level, and from a broad perspective, most legal scholars would tend to concur with this characterization of the administration of justice in the West. ${ }^{4}$ However, on a more specific level, does this rational goal model characterize the actual organization of criminal justice? Weber has charzcterized the major components of all organizations as: (1) a zontinuous organization of official functions bound by rules; (2) a specific sphere of competence, i.e., a sphere of obligations, in the division of labor to be performed by a person who is provided with the necessary means and authority to carry out his tasks; (3) the organization of offices following the principle of hierarchy; and (4) a set of technical rules and norms regulating the conduct of the offices (Etzioni, 1964: 43).

These conditions applied to the organization of the administration of criminal justice imply an elaborate apparatus which processes arrests according to highly defined rules and procedures undertaken by "experts" who perform the functions ascribed to them by highly defined formal roles, under a rigorous division of labor, and who are subject to scrutiny in a systematic and hierarchical pattern. This model seems to be the dominant view or ideal of the criminal justice process held by appellate judges and lawyers, and many of the academic students of the courts. Much of their discussion and research, 
therefore, has centered on the problems with the formal rules of operation, i.e., increasing the "rationality" by minimizing discretion and arbitrary administration, through specifying with increasing precision the roles of the actors. Lawyers under the auspices of the American Bar Association go to great lengths to articulate and refine the precise role of the advocate in criminal justice; many appellate court decisions are attempts at further defining and refining the rules and roles for the various actors in the oganization; law journals and appellate court opinions are filled with discussions of the proposals for rules to minimize discretion and more completely define the rules of procedure; and social scientists continue to point out that no one is following the formal rules.

One form of planning by utilizers of the rational-goal model is to examine and explicate the operative rules to determine whether or not they are internally consistent. Abraham Goldstein's discussion of the rules of criminal procedure is an excellent example of this type of analysis (1960). He attempts to show by logical analysis and example that certain alterations of the rules of criminal procedure have the effect of undercutting other, more generalized and basic rules and norms of "equality" among the parties. Since the system is conceived of as a meticulous application of highly defined and prescribed rules, Goldstein can convincingly argue this point, that certain alterations in procedure undercut the power of the defense and thereby weaken or destroy the more fundamental rule of "balanced advantage" between the adversaries. An analogy is that the equilibrium or balance of power in a game of chess is disturbed if a new rule permits White additional moves that are not granted to Black.

The rational-goal approach has not, however, concerned itself entirely with speculative and logical analysis of the rules and norms of the system; it has an empirical component as well. As Etzioni has noted, one of the major objects of the empirical studies adopting a goal model approach is to measure organizational "effectiveness" by contrasting observed, actual behavior with the stated, formal goals of the organization, and a good deal of social science research has followed this pattern.

Lefstein, Stapleton, and Teitelbaum's study of juvenile court judges' compliance to the Gault decisions is one example of this research (1969). Their basic format was to outline the requirements and implications of the Gault and related decisions, and then identify the extent to which the actual practices of judges 
in various jurisdictions and types of cases conformed to them. While they have demonstrated quite convincingly that the Gault decision had a major impact on the administration of juvenile justice, their optimism regarding the eventual full compliance to the standards of that decision seems somewhat unwarranted when one considers the practices of the actors in the administration of justice generally. What is not found in this study is an examination of the variety of factors, goals, and incentives operative (and likely to remain so) for the various individual actors in the system. A skeptical social scientist might well ask of a lower court judge, "So the Supreme Court handed down a decision, why should it affect you?" A full analysis of the dynamics of compliance and a theory of organization effectiveness would have to address itself to this question which assumes that the Supreme Court decision is just one of a number of factors affecting the system.

Likewise some of the studies reporting the impact of the Miranda decision on police behavior follow a similar format (Wald, et al., 1966-67, and Medalie, et al., 1968). The requirements specified in the decision are regarded as the formal goals and then actual behavior is observed and contasted with them. The studies report different levels of compliance and acceptance on the part of the police, but generally note a low level of effectiveness. Various factors are raised and suggested as possible bases for this less than complete compliance. The "newness" of the decision is one such mentioned factor. Another is the generally hostile attitude of the police toward the new requirements. These factors, however, are not examined systematically, nor are they - and others - incorporated into a dynamic model of organization which considers the multiplicity of goals and incentives operating simultaneously within the system.

My criticism of these types of empirical studies echoes Etzioni's criticism of the goal model approach in general. The preoccupation with a set of formal goals and the observation of behavior primarily in terms of how it squares with these goals (or how the rules have altered previous patterns of behavior) is not conducive to theory building and the explanation of the observed patterns of behavior. It tends to produce a unidimensional picture of the process by placing undue emphasis on one set of goals and rules without adequately considering other factors which are, perhaps, equally as important in shaping the behavior of the actors in the system. The shortcomings of this 
approach will become more evident as the functional-systems model is explicated and examples of it are discussed.

\section{FUNCTIONAL SYSTEMS APPROACHES}

Turning to the second model, the functional-systems model, a substantially different conception of organization is employed. A different set of practices tends to be focused on, and there is a far greater and explicit concern for "explaining" the behavior of the actors (as opposed to simply "contrasting" it). Etzioni has lumped together a wide variety of studies under the rubric of systems models, and here too, there is a wide variation in the approaches to the analysis of criminal justice which $I$ have placed in this category. There are, however, a number of common and distinguishing characteristics and assumptions which are shared by most of them. They all tend to view the organization of the administration of criminal justice as a system of action based primarily upon cooperation, exchange, and adaptation, and emphasize these considerations over adherence to formal rules and defined "roles" in searching for and developing explanations of behavior and discussing organizational effectiveness. Rather than being the primary focus of attention, formal "rules" and "disinterested professionalism" are viewed as only one set of the many factors shaping and controlling individuals' decisions, and perhaps not the most important ones. The efficacious "rules" followed by the actors are not necessarily the ideal, professional rules; and the goals they pursue are not necessarily the formal "organizational" goals posited by the researcher or even the "public" goals posited by the leaders of the organization.

Rather the "rules" the organization members are likely to follow are the "folkways" or informal "rules of the game" within the organization; the goals they pursue are likely to be personal or sub-group goals; and the roles they assume are likely to be defined by the functional adaptation of these two factors. These three features of the organization then are the objects to be accounted for, and the functional-systems approach is likely to begin to identify and examine the adaptation of the actors to the environment, the workload and the interests of the persons placed within the system, i.e., other goals of the actors within the organization.

The idealized perspective of the rational organization pursuing its single set of goals is replaced by a perspective of the set of rational individuals who comprise the system, in this case the prosecutor, defense counsel, police, defendant, clerks, etc. 
pursuing their various individual goals. Unlike the rational-goal model, this model explicitly recognizes the "normality" of, and emphasizes the reality of, conflict between formal organizational goals, and the goals of the individual actors within the organization. According to this model, the "authority" of legal rules and "professionalism" is not automatically assumed to be efficacious. A more complete system of incentives is required.

In order to account for the actual behavior and practices of the organization, the scholars who to varying degrees utilize this functional-systems model of organization, describe the actual process and then begin to identify and examine the causes and conditions of the patterns of behavior of the various actors. In doing this they focus on the working conditions, the system of controls, incentives, and sanctions at the disposal of the various actors, and the larger environmental effects on the system. However, beyond these very general sets of concerns, there is little in common among the scholars who use this functional systems approach of criminal justice administration.

As with the rational-goal model, analysts utilizing a functional-systems model also tend to be motivated by normative concerns, but they are more likely to move beyond the contrasting of ideal goals with actual practices, to search for and identify the factors contributing to the observed practices. While perhaps personally accepting one set of goals for the system and giving expression to their own values, the functional systems approach is at least open enough to allow for and acknowledge the existence of other goals, and not accept as "normal" the perfect coincidence of formal organizational goals with the goals of the individual actors within the system. Thus the perspective not only lends itself to accurate description of actual behavior but also begins to attempt to identify and account for the causes and conditions leading to this behavior.

Herbert Packer's recent book, The Limits of the Criminal Sanction (1968), dramatically illustrates one of the major points of the functional-systems analysts. There can be many "goals" operating simultaneously - and at odds with each other within any single system of organization, so that even to speak of "the formal goals" of an organization is likely to be misleading. He convincingly argues that there are at least two major sets of distinctly antagonistic values (the "due process" model and the "crime control" model) held by different actors responsible for administering criminal justice. One set emphasizes "due process," strict adherence to legal rules, and a full-fledged 
adversary relationship; the other emphasizes effective "crime control" for the community, and tends to minimize the concern for formality and individual rights. One's assessment of the "effectiveness" in achieving the "system's goals" would obviously depend upon which of the two sets of goals or models of values he subscribes to. Clearly any analysis of organizational behavior must be open-ended enough to identify and deal with the multiplicity of goals, values, and incentives of the various actors comprising the system. To do otherwise is likely to lead into the trap of reification and away from social theory.

Another body of research using a type of functional-systems approach tends to rely on an exchange model, adapted in varying degrees from Peter Blau's theoretical perspective (1964). The works of Jerome Skolnick (1966), Herbert Packer (1968), Abraham Blumberg (1967), and George Cole (1970) all tend to utilize this framework. The most widely-read work by any of these scholars is Skolnick's Justice Without Trial. While it is primarily an analysis of the functioning of the police in the realm of law enforcement, it does touch on police-prosecutor-court relationships, and characterizes them as participating in an elaborate exchange and bargaining system. However, in a related study, he focuses directly on the administration of criminal justice, and in particular on the roles, behavior, and relationships of the public defender and the prosecuting attorney (1967). For purposes of analysis he has suggested that all institutions are based either on norms of cooperation or norms of conflict, and that a major task of the social analyst is to identify and analyze means for countering these norms. That is, in an organization such as the family or corporation, a major concern is maintenance of cooperation and procedures for cooperation, and in other organizations, such as the sporting event or the adversary system, a major concern is maintenance of the institutionalized conflict and procedures for conflict. In both sets of institutions, Skolnick argues, the social analyst is interested in identifying the "deviation" from these norms of cooperation or conflict and the conditions and principles accounting for such deviation (Skolnick, 1967: 53). Thus his analysis focuses on the institutionalized and structural pressures to reduce the conflict between prosecutor and defense attorney, on the resulting functional adjustments, and also on the normative justifications that support these new practices which seem to violate the formal norms of conflict.

Skolnick (1967: 53) identifies the main pressures for "de- 
viant" cooperation in this system as administrative concerns of each of the sets of actors (e.g., the defense attorney wants to get the best deal for his client and also handle it in the most expeditious manner; the district attorney has many publics to satisfy, an enormous amount of work, and opportunity for a great amount of discretion in selecting cases and charges to develop). As a result, a strong tendency toward cooperation develops in the relationship that is theoretically portrayed as a zero-sum game. Strong informal norms to enhance the smooth functioning of the system itself replace the norms of conflict and adversarial relationship (Skolnick, 1967: 55). Thus, the main cause for the "deviation" from the conflict norms Skolnick identifies as administrative convenience, brought about through an elaborate exchange system of mutually advantageous benefits. Additionally, he notes that the prosecuting and defense attorneys (almost always young, inexperienced and idealistic lawyers) are usually "successfully" socialized into this through an elaborate system of informal controls, or are transferred out.

The main device in which all parties share an interest of administrative convenience is in settlement by a plea of guilty. This serves the administrative purposes of saving time, effort, and - the actors all usually emphasize - in "getting a better deal" for the accused. It also has the effect of replacing the adversary system's norm of "presumption of innocence" with a norm of "presumption of guilt." Skolnick, however, argues in regard to this point that cooperation does "not demonstrably impede the quality of representation," a phrase which is unfortunately quite vague. ${ }^{5}$ The operating norms - which rationalize this "deviant" behavior - at least from the public's or layman's perspective - are those of "administrative efficiency" and the "interests" of the accused in securing a reduced sentence.

Similar themes are taken up by other writers, who supply additional evidence to support a functional-systems model of the administration of criminal justice. Cole, in an analysis of the defense counsel/prosecutor relationships in Seattle, describes a similar system of mutually advantageous exchanges which function to displace conflict with cooperation, and produce a smooth-running system which seeks to maximize the administrative and personal goals of the individual actors rather than the formal organizational goals of due process. Stefan Kapsch (1971), in an interesting analysis which characterizes the plea bargaining by prosecution and defense as a mixed-strategy 
game-rather than the zero-sum game of adversary theory - emphasizes the administrative goals (the reduction of decision-making costs) being served by this substitution of cooperation for conflict, and also goes on to develop an explicit justification for the practice. ${ }^{6}$

Another well-known study of the administration of justice - and virtually the only recent full-length sociological analysis of the operations of a criminal court - is Blumberg's book on the New York City criminal justice system (1967). Despite his strong adherence to the principles enunciated in the "formal organizational goals" and particularly full-fledged adversary proceedings, Blumberg undertakes a functional analysis attempting to identify causes and conditions leading to the actual pracices. He does this by conceptualizing the organization (the court, as he terms it) as an elaborate system of exchanges by persons who can mutually benefit by cooperating. In a highly decentralized and complex organization, his model assumes that each of the actors will pursue more immediate goals and interests, and hence either the personal interests of the individual actor or the goals of and pressures for "production" and "efficiency" from his immediate supervisors and peer group will determine his actions. Thus, for example, the prosecutor's office wants high "batting averages," the defense counsel wants to handle cases as quickly as possible either for financial reasons or, in the case of the public defender, for administrative efficiency, and judges are constantly pressed to clear their calendars.

Blumberg identifies two main factors leading to the "displacement" of the formal, organizational goals by this system of mutual adjustment and exchange (1967).

Intolerably large case loads of defendants which must be disposed of in an organizational context of limited resources and personnel. ... As a consequence an almost irreconcilable conflict is posed in terms of intense pressures to process large numbers of cases on the one hand, and the stringent ideological and legal requirements of "due process" of law on the other hand. A rather tenuous resolution of the dilemma has emerged in the shape of a large variety of bureaucratically ordained and controlled "work crimes" short cuts, deviations and outright rule violations adopted as court practices in order to meet production norms (Blumberg, 1967a: 22).

Thus he has identified the press of large case loads and the strains on the actors as perhaps the chief reason for the systematic violations and/or tendencies to deviate from the prevailing ideological rules and norms of the adversary system. This makes it literally impossible for the actors to perform 
their prescribed roles, even if they wanted to. While it is no doubt accurate to identify a crushing case load as one of the factors necessitating functional adjustments and violations of the due process norms, the implication of Blumberg's argument seems to be that, in the absence of heavy case loads, the actors would "naturally" tend to perform their "proper" adversarial roles as defined by the full-fledged fight theory of the adversary system, and as outlined in some of the rational-goal models of the process.

This position is in at least partial conflict with Skolnick's and Cole's analyses of the conditions for cooperation (as opposed to institutionalized adversarial conflict), which emphasize the structural factors of long-term interaction, acquaintanceships, and a variety of personal and administrative factors (including handling of heavy case loads) as the primary factors contributing to a system of cooperation and exchange. Also, there is some evidence to indicate that rapid processing of defendants (and presumably "corner-cutting" by the actors in the system) occurs in situations where the work-load of the court is not pressing (Mileski, 1971). Thus I suspect that Blumberg has somewhat overstated the importance of heavy case loads, and perhaps as well, over-inflated the efficacy of "professional norms" of lawers, norms which he feels most criminal lawyers have been "forced" to abandon for the purposes of court-dictated expediency.

Blumberg is also interested in the defense counsel, whom he argues is ideally supposed to assume a highly defined "professional" role as advocate and champion of his client, but in fact is usually found - like the prosecutor, judge, and other court personnel - to respond to more direct and immediate incentives than those of "professional duty" (Blumberg, 1967a: 28).

The strong incentive of possible fee motivates the lawyer to promote litigation which would otherwise never have developed. However, the criminal lawyer develops a vested interest of an entirely different nature in his client's case: to limit its scope and duration rather than to battle. Only in this way can a case be profitable... In effect, in his role as double agent, the criminal lawyer performs an extremely vital and delicate mission for the court organization and the accused. Both principals are anxious to terminate the litigation with a minimum of expense and damage to each other.

This argument appears reasonable, and Skolnick's reports tend to corroborate it to some extent. However, one still wishes here that Blumberg had been more careful and systematic in collecting and evaluating his data and presenting his arguments 
on the incentives of defense counsel. His discussions of the two factors which undercut the full-fledged adversary role of the defense counsel, the heavy case load and the financial incentive to quick disposition of cases, tend to contradict each other. On one hand, he argues, the court, in an attempt to cope with the heavy case load, has "co-opted" the defense counsel and "forced" him into acting the part of a "confidence agent" in convincing his client to plead guilty. On the other hand, the discussion of the financial incentives indicates that regardless of the judge's and prosecutor's interests, it is still in the self-interest of the defense counsel to seek a quick termination of the case through a plea of guilty since he is usually paid a flat fee for representation. Consequently, the less time a case takes, the higher the volume of his income. If the financial incentive is an important one, then one would expect the defense counsel to willingly press for pleas of guilty regardless of case load before the court. Furthermore, it is not unreasonable to expect that up to a point, as case load diminishes, the defense counsel's desires for quick and cursory disposition of cases would tend to increase. If business is slackening, then one must hustle even more to maintain volume. Systematically gathered and presented evidence would go a long way toward resolving these rival plausible hypotheses and unsupported assertions. Still, on the whole, one is given the distinct impression from the works of Blumberg, Skolnick, and Cole that the defense counsel is not so much an unwittingly co-opted agent used by the self-serving court bureaucracy, as he is one of the key figures in an elaborate system in which everyone, including himself, has certain commodities to exchange in the pursuit of his own interests.

There is still another set of factors which has been identified and examined by many of the scholars adopting the functional-systems approach. This is the enormous amount of discretion possessed by most of the actors in the criminal justice system, and in particular, the police and prosecutor. Most analysts subscribing to the rational-goal model of the system make little mention of this, tending to emphasize the rational administration according to specified rules and assume that it is an "attainable goal." Likewise many "reformers" and advocates of increased "professonalism" (i.e., rule-following) avoid dealing squarely with the problem posed by discretion. Among those scholars who have focused on this problem, Joseph Goldstein (1969), Packer (1968), and Skolnick (1967) are the most prominent. What they have all noted is that the administrators of 
justice have tremendous leeway in defining a situation, a vast array of competing rules in their arsenal, and are placed in a situation where it is frequently physically impractical (if not literally impossible) to enforce or administer all, or perhaps even most, of the rules all of the time.

This problem of discretion has two main components: first is the problem of the sheer magnitude of substantive laws and procedural rules; second is the inherent ambiguity of rules. A moment's reflection tells us that it is physically impossible and undesirable in anything approaching a democratic society to attempt to enforce all rules - both substantive criminal law and due process norms in the administration of justice - all the time. There are simply too many rules, and it would require a police state, a totalitarian bureaucracy, and a highly costly apparatus to begin even to approach total enforcement. Therefore, given the virtual impossibility of faithful adherence to and enforcement of all the rules, there is considerable room for discretion in the enforcement and administration of the rules. Discretion in such circumstances is inevitable, and because of the low visibility of most of the criminal activities and administration, it falls primarily on the hands of the police and prosecutors, and is not subject to much public attention and continuous supervision.

The second component of discretion - the ambiguity of rules and the subsequent leeway in defining an action - is more complex and perhaps more philosophically intriguing. For instance, if a person is arrested for burglary, he could also be charged with intent to commit burglary, illegal possession of burglary tools, illegal entry, possession of stolen property, and numerous other criminal violations. In short, a single action can be defined and interpreted in a number of ways. The ambiguity of "facts," of course, further complicates the picture and enhances discretionary practices. The process of selecting which "facts" to consider and which "rule" to apply to define the activity is in itself a discretionary matter of considerable importance. The variety of available "legal" alternatives allows the actor a wide latitude for discretion, and of course a very valuable commodity to bargain with in the system of exchange. In this view the interpretation and use of the rules themselves are viewed as instruments of rationalization, not application. That is, the rules are selected and used as weapons or supports at the whim of, and in the particular interests of, the various actors in the system. Thus ambiguity and discretion are inherent 
to the very nature of all elaborate systems of rules, and "force" enforcement and administrative officials - the so-called rule "appliers" - into a position of making "lawless" decisions. This poses a major problem in the administration of justice, as Herbert Packer (1968: 290) has noted:

The basic trouble with discretion is simply that it is lawless, in the literal sense of that term. If police or prosecutors find themselves free (or compelled) to pick and choose among known or knowable instances of criminal conduct, they are making a judgment which in a society based on law should be made only by those to whom the making of law is entrusted.

To the extent that this in fact is the case - for the reasons just outlined - a faithful adherence to a rational-goal model of the criminal justice system is impossible in practice and in principle.

\section{CONSIDERATIONS FOR REFORM}

While analysts using the rational-goal model have tended to emphasize the set of formal goals, ideals, and rules which they suggest should be operating in the administration of justice, and have examined the consequences of non-performance of these goals in terms of the normative ideals and consequences to individual rights, they have frequently ignored the factors and conditions contributing to the displacement, violation, and non-performance of these goals, ideals and rules. ${ }^{7}$ On the other hand, the functional-systems approach has gone a long way toward identifying the causes and conditions accounting for the observed behavior, and toward demonstrating that there is no particular reason to expect individual's behavior to coincide with the behavior prescribed by the formal goals of the system. Formal rules and norms obviously affect and guide the behavior of the actors, but they are only one set of considerations among several.

It is therefore unreasonable to expect a perfectly "effective" system for administering criminal justice. This, of course, does not preclude the adoption of policies and practices which incrementally increase the system's "effectiveness." Additional rules of clarification and procedure, reducing the reliance on the criminal sanction, more and better trained personnel, more space, and improved calendars, are all frequently mentioned as measures of reform, and there is little question that their adoption would result in improvement. However, running through such proposals is the assumption that if these steps were taken, the actors in the system would somehow naturally begin to assume stronger commitments to the formal goals 
and rules of the system and act accordingly. This tends to underestimate, I think, the very real and strong individual and sub-group incentives, goals, and values, and underestimates as well the saliency of the "crime control model" as the operative normative ideal among many persons involved in the system. Clearly it is more than a problem of overcoming work-load so that good men can do good work. There exist strong competing norms and incentives which act at cross-purposes to the system's formal goals and norms. The task of institutionalized reform rests squarely on the generation of mechanisms which strengthen the position of the organizational goals and norms vis-a-vis the competing subgroup and individual goals.

At this point it is particularly useful to return to the concerns of the theorists of large-scale organizations, and begin to consider some of the structural features of the system, particularly the compliance-inducing mechanisms. What emerges from the analysis of the operations of the criminal justice system is a clear picture of an organization which has highly specified rules and goals, but has virtually no instruments by which to enforce them. Rather than the highly rationalized, rule-bound and bureaucratically structured system that Weber depicted the process to be, one finds a highly decentralized and decidedly non-hierarchial system of exchange, in which there are virtually no instruments to supervise practices and secure compliance to the formal goals of the organization. In the absence of such efficacious compliance securing mechanisms, institutionalized long-term reform is unlikely.

Only two mechanisms are institutionalized to induce actors to comply with the formal rules and goals of the criminal justice system - normative inducements accruing from professionalism and the appellate procedure - and neither is very effective in relation to the countervailing incentives.

Appeal to the normative considerations of professionalism is a key source of control in many organizations composed of highly trained and skilled personnel, and in many instances is a highly successful instrument. Certainly the guild-like pride and clannishness of the legal profession generally and bar associations in particular act as a powerful influence on lawyers. Legal training is marked with a continuing emphasis on the professional responsiblities of the lawyer and one might expect all these factors to act as a substantial "professionalizing" influence on the actors in the criminal justice system. However, a great many students of professional organizations 
have noted that the importance of professional norms - in the absence of direct supervision and other formal means of control-are not as powerful as they are popularly believed to be.

This downward revised assessment would particularly seem to be the case in the administration of criminal justice. There is little disagreement among knowledgeable observers that the criminal lawyer - including the office of prosecutor, defense lawyer, and not infrequently the criminal court judge as well - holds the status of anchor-man within the legal profession. This certainly acts to reduce the importance of the norm of "professionalism" as a compliance-inducing mechanism. Likewise, the low visbility of the administration of criminal justice and the generally "low" status of its clients tends to further erode the "professional" environment and leads to a lack of concern on the part of the more prestigious legal professional organizations and the public generally, further undercutting one of the major sources of inducement to professionalism.

The other mechanism - the only formal one - institutionalized to induce compliance to formal organizational norms on the part of the actors within it, is the appellate process, and the continuing opportunity for appeal. This, however, is a highly ineffectual instrument in that it is relatively passive, extremely expensive, can be instituted only at the insistence of a convicted defendant, and usually only if it is pressed by his defense counsel. At best it is a passive instrument, which might function to curb some of the most flagrant violations of administration, but is hardly a powerful and systematic instrument of control in most instances.

In short, what one finds in the system of criminal justice is a highly formalized and defined set of rules, norms, and goals, but also an organization which possesses no corresponding set of incentives and sanctions which act to systematically enforce them. Any far-reaching discussion of reform and proposals for change in the administration within the American system of criminal justice would have to deal with this problem of the nature and distribution of compliance-including mechanisms. ${ }^{8}$ Ironically, it seems to lead to a solution requiring more bureaucracy, not less.

\section{FOOTNOTES}

1 I have been criticized on this point by some persons who argue that the American adversary system cannot be considered an "organization," and in fact is designed explicitly to avoid "organizational" and "bureaucratic" processing of cases on a routine basis. The argument is that 
the adversary system protects individual rights by institutionalizing the lack of an organization to "process" cases, in contrast to (to varying degrees) many of the countries relying on inquisitorial methods. While there are certainly differences between European and American practices in the administration of criminal justice, I think that these differences are easily contained within an organizational framework. One system may be more centralized and hierarchically organized than another, but in all cases there is a group of institutionalized interacting roles which in principle are expected to work together (whether through conflict or cooperation) toward a common set of goals.

2 Herbert Packer (1968) makes a similar point in his discussion of the two models of criminal justice, the "due process" model and the "crime control" model. He suggests that among academic lawyers, the former tends to be regarded as the "goals" of the system. Likewise John Rawls has made a similar point (1958).

3 No doubt one of the major reasons for concentrating almost exclusively on "means" - aside from their connection with the concept of justice - in analyzing the activities of the criminal justice system is that there is no way of measuring effectiveness in terms of deciding guilt or innocence, another activity which might reasonably be identified as the "goal" of the organization. That is, if one posed this as the goal of the organization, there would be no reliable measure which would allow him to contrast the "ideal" with the actual in that there is no way of always knowing factual guilt or innocence.

4 This position, on a general level, reflects Maine's (1963) celebrated observation that the "movement of the progressive societies has hitherto been a movement from Status to Contract." Likewise similar division of labor and specialization of the administration of justice has been demonstrated systematically in the work of Schwartz and Miller (1964) and Schwartz (1954). On the other hand, many scholars question the extent to which all this has in fact taken place. The legal realists have rather successfully demonstrated the ambiguity of legal rules and the flexibility of rule-application (Llewellyn, 1964). Likewise the judicial behaviorists have rather convincingly demonstrated a relationship between judicial backgrounds and judicial behavior (see Schubert, 1965 , and Nagel, 1970). Also, Friedman (1966) has challenged and at least modified Weber's arguments regarding the nature of "rational" legal reasoning, and along with Joseph Goldstein (1969) and others has shown the increasing utilization of discretionary, non-rule specified powers within the "modern" law. Kadi-like justice seems not to have disappeared either in theory or in fact.

5 At any rate, this argument should have been dwelt on in more depth. He offers no real evidence for it, nor does he attempt to operationalize "quality of representation," and it remains an undemonstrated assertion. It is, I think, an example of the conservative bias, i.e., the acceptance of the status quo once one "understands" it, which if not inherent in the logic of functional analysis generally is certainly reflected in a good deal of functionalist literature.

6 I think that his is a tortured reading of the traditional theory of the adversary system and the administration of justice, but nevertheless it is one of the few thoughtful discussions of the practices - one that moves away from implicit normative support of the practices, and begins to offer an explicit justification of them.

7 This language assumes that if there is widespread consensus that these are, in fact, the actual goals of the organization, and that they once were - or could have been - achieved. Packer's persuasive analysis of the two models of criminal justice points up the existence of a multiplicity of goals within the organization, and shows that they frequently lead to cross purposes.

8 For an elaboration of the problem of individual incentives and compliance inducing mechanisms, see my discussion of law as a "public good," and the subsequent problem for an explanation of individual incentives and compliance (Feeley, 1970). For a general exposition of the problem of incentives and compliance to organizational goals by "rational actors," see Downs (1967).

\section{REFERENCES}

BLAU, P. (1964) Exchange and Power in Social Life. New York: John Wiley. 
BLUMBERG, A. (1967) Criminal Justice. Chicago: Quadrangle Books.

(1967a) "The Practice of Law as a Confidence Game," 1 Law and Society Review 15-29.

COLE, G. (1970) "The Decision to Prosecute," 4 Law and Society Review 331-345.

DOWNS, A. (1967) Inside Bureaucracy. Boston: Little Brown.

ETZIONI, A. (1960) "Two Approaches to Organizational Analysis: A Critique and a Suggestion," 5 Administrative Science Quarterly 257-278.

(1961) A Comparative Analysis of Complex Organizations. New York: Free Press.

Hall.

(1964) Modern Organization. Englewood Cliffs: Prentice

FEELEY, M. (1970) "Coercion and Compliance," 4 Law and Society Review 505-519.

FRIEDMAN, L. (1966) "On Legalistic Reasoning - A Footnote to Weber," 1966 Wisconsin Law Review 148-171.

GOLDSTEIN, A.S. (1960) "The State and the Accused: Balance of Advantage in Criminal Procedure," 69 Yale Law Journal 1149-1199.

GOLDSTEIN, J. (1969) "Police Discretion Not to Invoke the Criminal Process: Low Visibility Decisions in the Administration of Justice," 69 Yale Law Journal 543-594.

KAPSCH, S. (1971) The Adversary System and the Assistance of Counsel. Unpublished Ph.D. Thesis, Department of Political Science, University of Minnesota.

KLONOSKI, J. and R. MENDELSOHN (eds.) (1970) The Politics of Legal Justice. Boston: Little Brown.

LEFSTEIN, N., V. STAPLETON, and L. TEITELBAUM (i969) "In Search of Juvenile Justice," 5 Law and Society Review 491-563.

LLEWELLYN, K. (1960) The Common Law Tradition. Boston: Little Brown.

MAINE, H. (1963) Ancient Law. Boston: Beacon Press.

MEDALIE, R.J., et al. (1968) "Custodial Police Interrogation in Our Nation's Capital: The Attempt to Implement Miranda," 66 Michigan Law Review 1347-1422.

MILESKI, M. (1971) "Courtroom Encounters," 5 Law and Society Review 473-538.

NAGEL, S. (1970) The Judicial Process from a Behavioral Perspective. Chicago: Dorsey.

PACKEK, H. (1968) The Limits of the Criminal Sanction. Stanford: Stanford University Press.

RAWLS, J. (1958) "Justice as Fairness," 67 Philosophical Review 164-197.

SCHUBERT, G. (1965) The Judicial Mind. Evanston: Northwestern University Press.

SKOLNICK, J. (1966) Justice Without Trial. New York: John Wiley.

(1967) "Social Control in the Adversary System," 11 Journal of Conflict Resolution 52-67.

SCHWARTZ, R.D. (1954) "Social Factors in the Development of Legal Control," 63 Yale Law Journal 471-491.

and J. MILLER (1964) "Legal Evolution and Societal Complexity," 70 American Journal of Sociology 159-169.

WALD, M.S., et al. (1966) "Interrogations in New Haven: The Impact of Miranda," 76 Yale Law Journal 1521-1648.

WEBER, M. (1954) "Rational and Irrational Administration of Justice," in Max RHEINSTEIN (ed.) Max Weber on Law in Economy and Society. Cambridge: Harvard University Press. 
HeinOnline -- 7 Law \& Soc'y Rev. 426 1972-1973 